\title{
Pedro de Mena. Granatensis Malacae
}

Palacio Episcopal (Málaga)

Del 16 de marzo al 14 de julio 2019

Málaga está de reencuentro y celebración en este 2019 con la «vuelta» de Pedro de Mena a la ciudad que le dio fama hace tres siglos. Desde hace casi dos años Palacio Episcopal Málaga. Centro de Arte ha estado gestando la que hasta día de hoy es la mayor exposición realizada en este espacio de arte perteneciente al Obispado de Málaga y que abrió sus puertas hace un lustro. La muestra se celebra entre el Palacio Episcopal y el Coro de la Catedral de Málaga. Esta retrospectiva, con vocación internacional, ha sido posible gracias a un amplio equipo de profesionales encabezado por Gonzalo Otalecu Guerrero, gerente de Palacio Episcopal y comisariada por José Luis Romero Torres, doctor en Historia del Arte y conservador de Patrimonio Histórico de la Junta de Andalucía [1].

La exposición la conforman 63 piezas procedentes de diversas instituciones nacionales e internacionales como el Museo Nacional del Prado, el Museo Nacional de Escultura, el Musée National d'Historie et d'Art de Luxemburgo, o el Museu Nacional d'Art de Catalunya, entre otros. Por otro lado, un grupo heterogéneo de coleccionistas particulares y centros eclesiásticos han permitido, gracias a su generosidad, enriquecer aún más la muestra con obras que en casos concretos siguen al culto, siendo más difícil su cesión para una exposición temporal. Entre ellas destacamos la Colección Granados de Madrid, las catedrales de Málaga, Granada, Córdoba, Toledo y Cuenca y un número bastante amplio de iglesias parroquiales y conventos españoles. La exposición de Pedro de Mena. Granatensis Malacae llega a Málaga 30 años después de la famosa muestra del mismo autor celebrada en nuestra ciudad junto con un congreso nacional. Esta vez, con mayor cantidad de piezas, pero en la misma ciudad que acogió a este escultor granadino afincado en un taller de la calle Afligidos, a escasos metros de la Catedral.

El discurso expositivo se centra en seis bloques organizados con un criterio iconográfico, a excepción de los dos primeros, que contextualizan al autor en su entorno. La muestra se abre con «ldentidad», donde se explica la autoconciencia de Mena como creador artístico. El autor solía

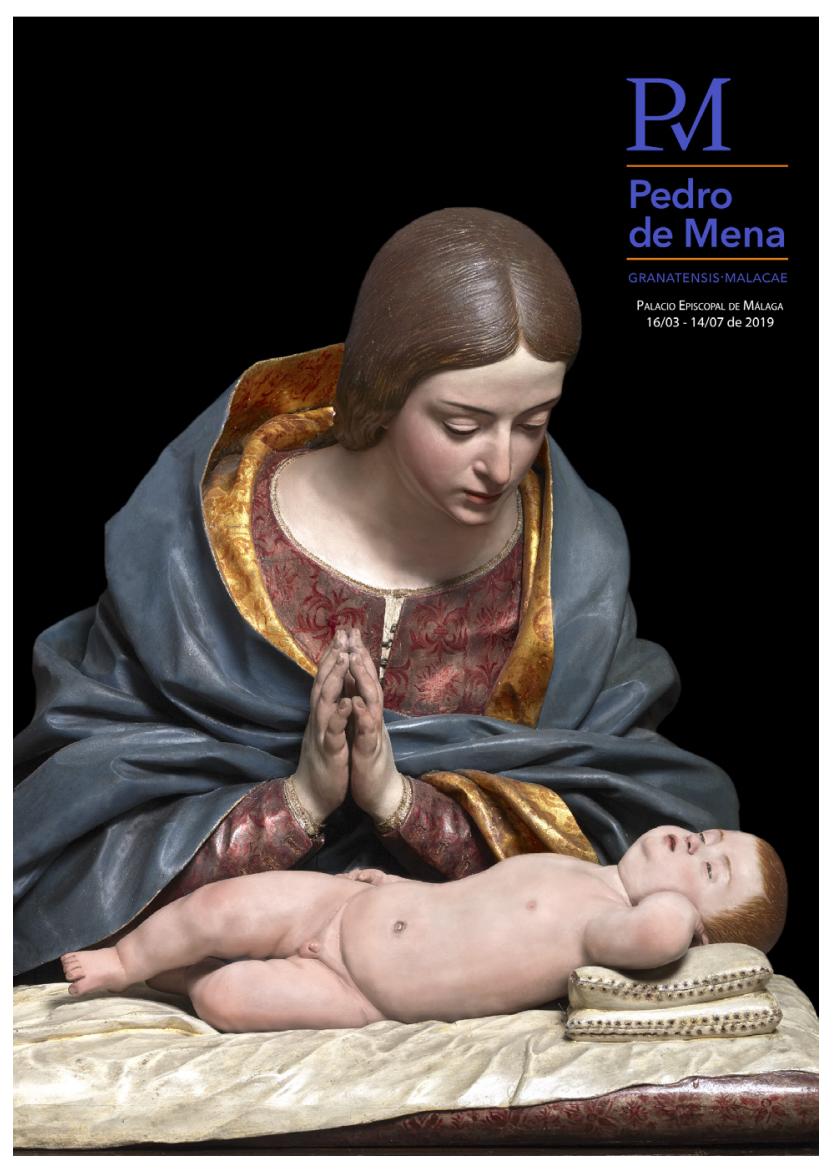

1. Cartel de la exposición

dejar huella de su autoría, procedencia y lugar de realización en algunas de sus obras, como podemos ver en el San Juan Bautista Niño procedente del Museo de Bellas Artes de Sevilla o en la Inmaculada Concepción del Palacio Arzobispal granadino. Esta valoración de la profesión artística a través de la firma es infrecuente en el contexto artístico del s. XVII y más propia del s. XIX en adelante. Una de estas placas autografiadas es la de La Magdalena Penitente, reproducida en grande en esta misma sala. En ella nos encontramos con la expresión que da título a la exposición, Granatensis Malacae (un granadino en Málaga). 


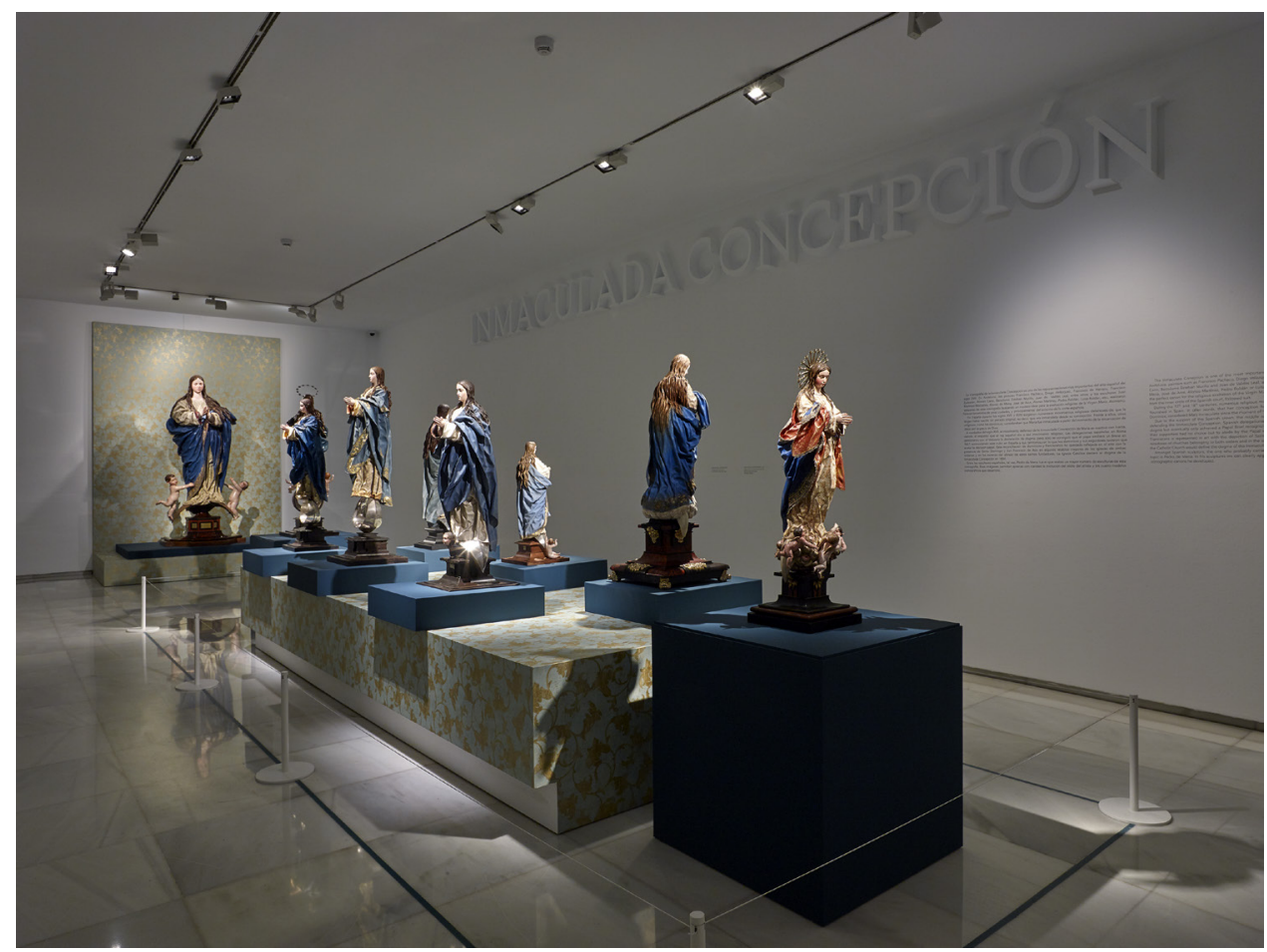

2. Vista general de la sala «Inmaculada Concepción»

En la sección siguiente «Amigo y protector» se pone en contexto la relación de Pedro de Mena con Málaga y sobre todo con sus benefactores más cercanos, destacando a Fray Alonso de Santo Tomás, prior de la Orden de los Predicadores en la ciudad y obispo en la misma. Sería el comitente de obras clave del artista como el Cristo de la Buena Muerte y la Virgen de Belén, ambos desaparecidos pero recordados a través de sendas fotografías coloreadas en la sala. Además, junto a la pareja de Los Reyes Católicos orantes de la catedral malagueña, nos encontramos con la única obra no realizada por Pedro de Mena, un retrato atribuido a Maíno con la efigie del fraile dominico procedente del Museu Nacional d'Art de Catalunya.

El espacio que le sigue, «Inmaculada Concepción», presenta la evolución artística de Pedro de Mena con uno de los tipos iconográficos más importantes del arte hispánico durante el seiscientos. Junto con Murillo, Mena fue el artista más interesado y solicitado por la clientela artística de este tema, con más de una veintena de versiones escultóricas. Junto con la de la primera sala, se reúnen diez Inmaculadas que explican las variaciones estilísticas del autor, partiendo con los prime- ros modelos, como la del Seminario Diocesano de Málaga o la del convento toledano de la Purísima Concepción, ambas fuertemente influenciadas por su maestro Alonso Cano. Éstas y las demás imágenes tienen en común el interés de Mena por incidir en la belleza del rostro juvenil de María, su dulzura y en el virtuosismo artístico a la hora de tratar el movimiento de las telas que la cubren. Por otro lado, cabe destacar la exquisitez con la que el granadino realiza los mechones de la cabellera de María en sus Inmaculadas más personales, como la de Palacio Episcopal de Málaga, la de la iglesia de San Nicolás de Murcia o la del convento de las Carmelitas Descalzas de Santa Teresa de Jesús en Madrid. Por último, una imponente Inmaculada Concepción de tamaño natural se dispone al final de esta sala, siendo ésta la última obra producida por Pedro de Mena. La talla, ubicada en la iglesia de San Juan Bautista de Marchena (Sevilla), fue concluida por Miguel de Zayas, heredero del taller de la calle Afligidos. A destacar la museografía de la sala, en la que ninguna Inmaculada destaca sobre otra a la vez que se va presentando la evolución estilística del maestro desde las primeras tallas de corte "canesco» hasta su obra final para Marchena [2]. 
Subiendo a la primera planta nos encontraremos con "Maternidad e Infancia de Jesús», un espacio en el que recorremos los primeros años de la vida de Cristo, solo o en compañía de su madre y padre «adoptivo». En general se quiere hacer hincapié en la importancia que adquieren estas representaciones tan tiernas y humanizadas de la divinidad en el contexto de la Reforma Católica tras el Concilio de Trento. Esculturas como el San José con el Niño de la iglesia de San Nicolás de Murcia, la Virgen de Belén de la Catedral de Granada o la Virgen orando frente al Niño de la Colección Granados ponen de manifiesto la doble naturaleza de Cristo, humana y divina. De cómo ese niño requería de los cuidados y el cariño de sus padres, pero sin olvidar su condición de Hijo de Dios, de ahí la posición orante de la Virgen en varias ocasiones o el hecho de que San José nos lo presente en sus brazos a modo de custodia. Del mismo modo Pedro de Mena representa al Salvador exento, como podemos ver en un magnífico Niño Jesús dormido de la Colección Alberto Martín de los Ríos o en el excepcional Niño Jesús triunfante del Musée National d'Histoire et d'Art de Luxemburgo.

El granadino es célebre principalmente por sus series de Ecce Homos y Dolorosas que pueblan decenas de iglesias, conventos, colecciones particulares y museos nacionales e internacionales. La exposición reúne diecisiete de estas piezas procedentes de diversos lugares de la geografía española, como Valladolid, Sevilla, Granada, Cuenca o la propia Málaga. De busto, hasta el pecho y hasta la cadera, son las tres tipologías que Mena realizara de estos temas, estando bien representadas en esta sala. Además, dada la prolífica actividad del maestro y su taller, podemos comparar cómo las calidades de ejecución en ocasiones podrían ser dispares. Por otro lado, cabe destacar la museografía diseñada por Miguel Ángel Blanco con el asesoramiento del comisario, especialmente en esta sala, desprovista de cualquier elemento accesorio que pueda distraer la atención del espectador, apostando por la tonalidad clara en la pared, suscitando una mayor sensación de espiritualidad a la hora de contemplar las obras. Aquí destacan dos magníficas piezas de reducidas dimensiones procedentes del Palacio de San Telmo (Sevilla), en las que el dolor contenido de Cristo y María se hace latente para provocar en el fiel la compassio necesaria que suscitase los sentimientos de devoción y oración ante la imagen. Esta sala da inicio a la sección «Pasión de Cristo» culminando en la estancia siguiente con dos obras

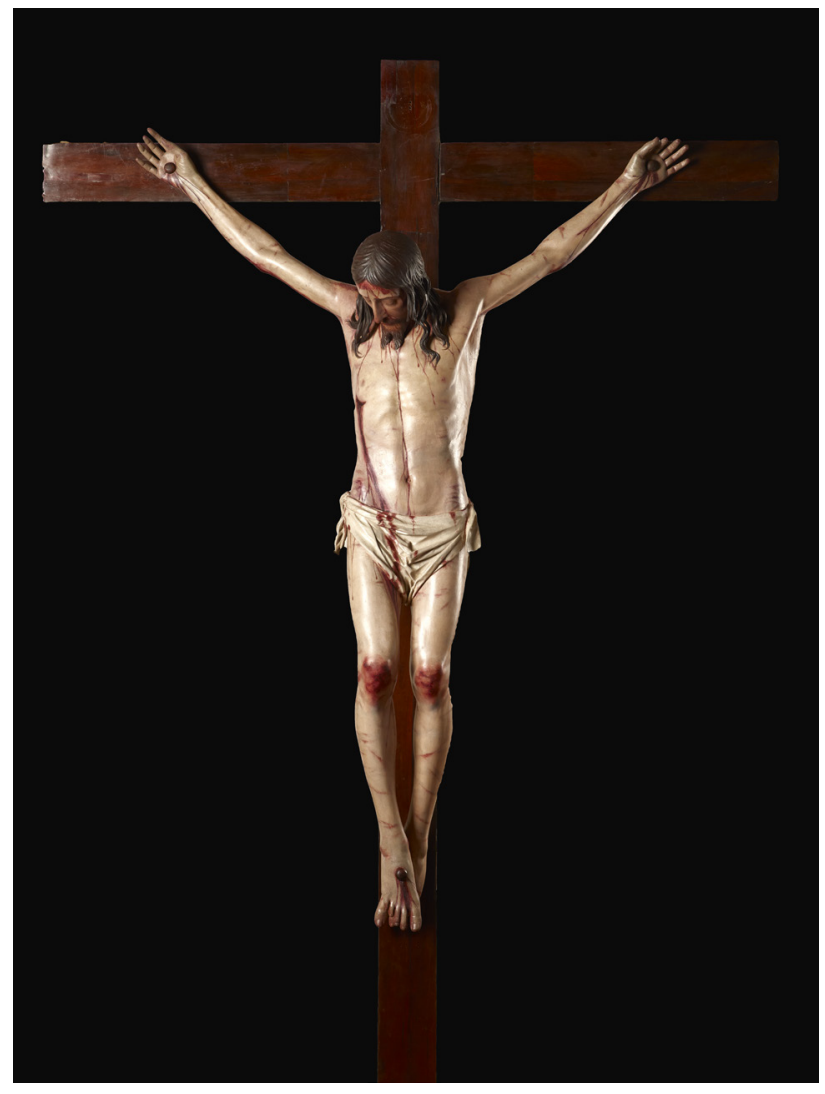

3. Cristo del Perdón

que marcan uno de los puntos destacados de la muestra. El Cristo del Perdón y la Mater Dolorosa, ubicados en la seo malacitana se reencuentran con el gran público malagueño después de haber sido magníficamente restaurados por Francisco Naranjo y Ángeles Mulero, que han eliminado burdos repintes que sufrió la imagen del Cristo y han devuelto el magnífico cromatismo de las vestiduras de la Virgen. Este Cristo crucificado se presenta como la versión «malagueña» del "canesco» y desaparecido Cristo de la Buena Muerte, con un mayor interés por el naturalismo y el realismo anatómico del representado. Ambas imágenes, separadas tras la Guerra Civil, vuelven a unirse en esta exposición tal y como las concibió Pedro de Mena, en una instalación efímera a modo de capilla que genera la sensación de recogimiento propias de su disposición original en un oratorio familiar. Esta pieza tradicionalmente se había atribuido al taller de Mena, pero tras la limpieza de la misma sale a la luz la policromía original que, en palabras del comisario, entra en relación di- 


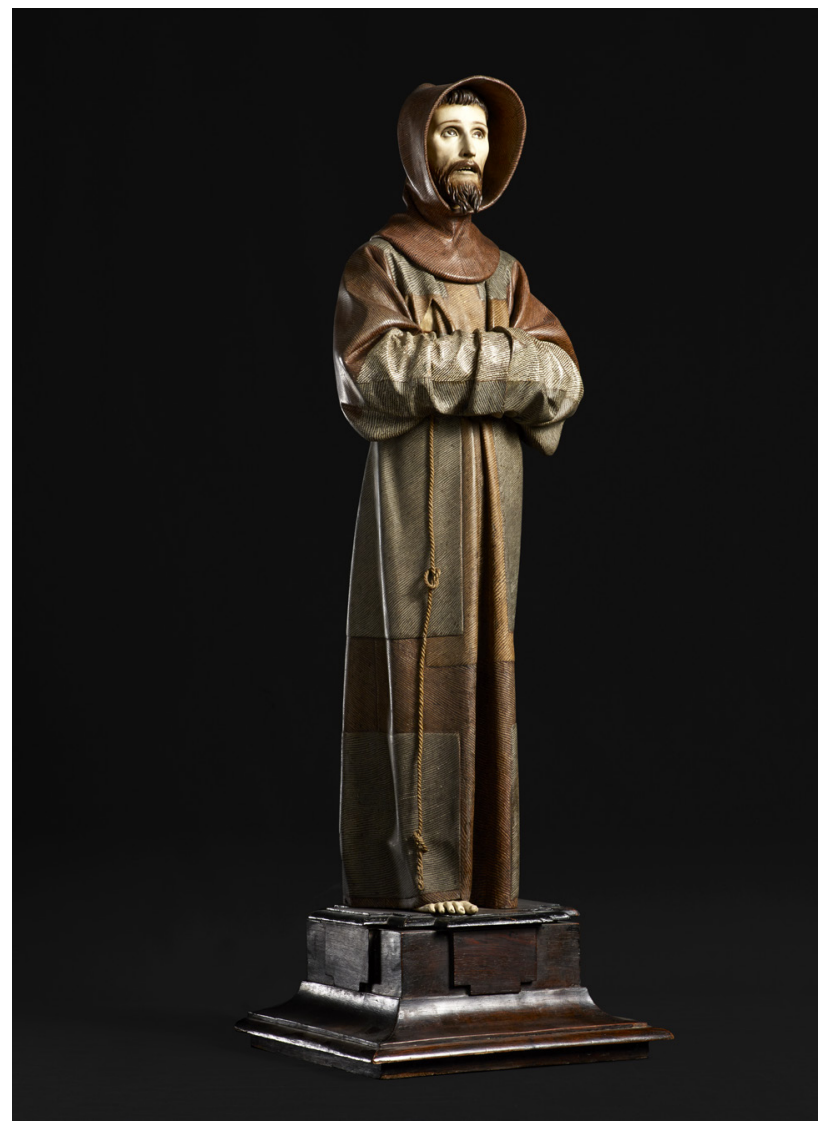

4. San Francisco de Asís. Catedral de Toledo. 1663

recta con Pedro de Mena, por lo que ha podido atribuirlo al maestro granadino [3].

Punto y aparte, para la última sección de la exposición «Ejemplos de Santidad» (entre la planta baja y planta primera), nos encontramos con interesantísimas esculturas de santos y santas de la Iglesia católica que se convierten en modelos de imitatio tras el Concilio de Trento por encarnar valores que refuerzan las verdades de fe del dogma católico. Así, veremos magníficos ejemplos de ascetismo, vida espiritual, entrega a Dios y a los hombres en casos concretos como Santa Teresa de Jesús de la iglesia cordobesa de San Pedro de Alcántara, San Pedro Mártir de Verona de la iglesia de la Asunción de Cabra, San Pedro de Alcántara de la iglesia de franciscanos de Madre de Dios en Lucena o los archiconocidos san Franciscos. En lo referente a la sala dedicada al santo de Asís, destacamos la imagen procedente de la Catedral Primada de Toledo, una de las creaciones más populares del granadino a la vez que de las más virtuosas, en las que representa al patrón de Italia incorrupto y con los ojos dirigidos hacia el cielo, en la misma posición que según la leyenda milagrosa lo encontró el papa Nicolás $V$ trescientos años después de su muerte [4].

Por último y como piezas angulares de la exposición contamos con dos obras maestras de la escultura barroca española que marcan el colofón de la muestra: La Magdalena Penitente del Museo Nacional del Prado (en depósito en el Museo Nacional de Escultura de Valladolid) y la Sillería del Coro de la Catedral de Málaga. La santa se sitúa a mitad de la sección «Ejemplos de santidad», en una sala circular en penumbra que recrea la cueva en la que, según la Leyenda Áurea, se retira después de los acontecimientos de la Ascensión de Cristo. Obra paradigmática del Barroco europeo, es coetánea y comparable a la mejor producción de Bernini. Mena es capaz de plasmar magistralmente los affetti en una santa que se convierte en modelo de imitación en lo referente a la penitencia para todos los católicos.

A modo de epílogo, la sillería del coro catedralicio se convierte en la última «sala» de este recorrido por la producción de Pedro de Mena; su gran obra de conjunto, en la que supo desplegar todas sus dotes como escultor con 42 piezas que empezaron a fraguar la leyenda de aquel Granatensis Malacae del que se celebra esta magnífica exposición 331 años después de su muerte.

Por último, el interés científico y educativo de la exposición ha sido bastante alto, con la edición de un magnífico catálogo de 350 páginas en el que colaboran José Luis Romero Torres, Juan Antonio Sánchez, M. a Dolores Blanca López, Miguel Ángel Gamero Pérez, Manuel García Luque y Patrick Lenaghan con diversos ensayos sobre la obra y el quehacer de Mena y exhaustivas fichas técnicas de cada una de las piezas expuestas. Por otro lado se ha organizado un ciclo de conferencias organizado por el catedrático en Historia del Arte Juan Antonio Sánchez López en el que participan distintos docentes universitarios y profesionales del ámbito cultural con ponencias diversas sobre el escultor granadino. Además, como colofón de la exposición, una serie de conciertos con música europea de la época de Pedro de Mena se celebran entre la Catedral y el Palacio Episcopal.

José Manuel Leiva Aldea Universidad de Málaga 